\title{
As chaves de casa de $A$ chave de casa
}

Iza Quelhas ${ }^{1}$

Vagner Rangel ${ }^{2}$

Flavia Bomfim ${ }^{3}$

Marilene Costa ${ }^{4}$

Resumo: Este texto representa um esforço para pensar a produção romanesca modernocontemporânea sob o rótulo de escrita autobiográfica, confessional e autoficção; tratam-se de categorias distintas na tecelagem literária e representam um olhar para trás a fim de reavaliar o mundo e/ou se integrar ao mesmo numa espécie de "redenção-sem-deus". Isso porque o sujeito contemporâneo, marcado ainda mais pela fragmentação da infraestrutura e superestrutura que sustenta/va o pensamento da Idade Moderna, se projeta na sociedade chamada pós-moderna, ainda que, paradoxalmente, os mitos continuem presentes em seu imaginário. A partir daí, trabalharemos com o romance $A$ chave de casa, de Tatiana Salem Levy (2009), publicado pela editora Record, e o texto crítico-literário de Silviano Santiago (2011), "Meditação sobre o ato de criar".

Palavras-chave: Literatura contemporânea. Discurso autobiográfico. Discurso confessional. Autoficção. Identidade.

\section{Introdução}

A chave de casa é uma narrativa não linear em primeira pessoa, chamada pela autora, Tatiana Salem Levy (2009), de autoficção, visto que a personagem principal tem muito em comum com a sua própria vida. Ambas nasceram em janeiro de 1979, no exílio (Portugal), numa época em que seus pais fugiam da ditadura militar instaurada no Brasil. Ambas voltaram ao Brasil nove meses depois e são descendentes de turcos. A partir daí, mistura-se vida real com ficção, ou melhor, a vida "real" torna-se ficcionalizada. Os leitores

\footnotetext{
${ }^{1}$ Professora Associada, atua nos cursos de Letras da Faculdade de Formação de Professores da UERJ, na Pós Graduação em Educação Básica e na Pós-graduação em História Social. Tem experiência acadêmica na área de Letras, com ênfase em Literatura Brasileira e Literaturas em Língua Portuguesa. E-mail: prof.iza.quelhas@gmail.com.

${ }^{2}$ Pós-graduando em Estudos Literários pela UERJ-FFP. Foi bolsista de Iniciação Científica PIBIC/UERJ. Como resultado da pesquisa, publicou os artigos "Frankfurt e french fries: sobre a crise da razão", na Revista Anagrama (USP) e "O Nome da Rosa, de Umberto Eco: questões em torno do (pós?) moderno", em coautoria com a orientadora, na Revista Soletras impressa. E-mail: vagnner.rangel@ gmail.com.

${ }^{3}$ Professora de Língua Portuguesa, Literatura e Redação de Ensino Fundamental, Ensino Médio e pré-vestibular em redes privada e pública no RJ. Especialização em Língua Portuguesa pela FFP da UERJ (2003). Atualmente cursa pós-graduação em Estudos Literários pela mesma Instituição. E-mail: flaviamaiabomfim@ yahoo.com.br.

${ }^{4}$ Graduada pela Universidade Estácio de Sá (2007). Participou do X Congresso internacional da Abralic/2006. É pós-graduada em Literatura Francófona pela UFF e está cursando o curso de pós-graduação em Estudos Literários na UERJ, com previsão de conclusão para setembro de 2013. E-mail: maricosta65@ hotmail.com.
} 
acompanham a trajetória de uma moça à procura de preenchimento para suas lacunas, de chaves para o seu self: suas origens, sua herança, a cura para as suas dores, o seu estilo para escrever através de uma viagem que empreende até a Turquia e de outra viagem através de seu processo de escrita.

\section{As viagens: metafórica e literal}

Num rápido brainstorming a fim de intitular este trabalho, veio à tona o nome As chaves de casa de A chave de casa, porque a personagem-narradora, que não é nomeada ao longo do romance, embarca em quatro viagens que são, de certo modo, como chaves (caminhos) para sua redenção sem o Deus cristão:

Não havia nada de religioso no ritual. Para mim, faltava sempre alguma coisa. Faltava verdade. Tudo não passava de uma grande encenação: éramos judeus um dia por ano. Festejávamos o ano-novo, mas para nós o ano só começava no dia primeiro de janeiro. $\mathrm{O}$ ano nunca começou em setembro ou outubro. Então, por que a celebração? Por que esse teatro para nós mesmos? [Não entendo por que dizer que não havia verdade. Deus não estava na mesa, concordo, foi a nossa escolha. Não era a religião o que nos importava, mas a tradição. Não queríamos simplesmente jogar na lata de lixo aquilo que nossos antepassados se esforçaram para guardar. O importante era manter a simbologia. Eu queria transmitir um pouquinho do que aprendi para os que vieram depois (LEVY, 2009, p. 130).

No entanto, algumas viagens são literais, como a viagem à Turquia e a Portugal. Outras são metafóricas, como a morte física e a vida memorialística da mãe; uma vez morta, ela, a mãe, vive exclusivamente através da memória da filha, gera um intenso diálogo da personagem com o subconsciente, de forma que, durante a leitura do romance, leva-nos a crer que representaria uma provável reação (mas não certa) da mãe a respeito das ações da filhanarradora, a personagem central:

Não há nada que me angustie tanto quanto me despedir de alguém: tchau, adeus, au revoir, até breve, até nunca mais. Quando eu era pequena, quando mal sabia dar nome ao que sentia, você partia toda manhã. Como partem todos, de manhã cedo, depois do café. Sabia que voltaria à noite, mas e se não voltasse? Cada manhã, a mesma dor, o mesmo choro: por favor, não parta, não me deixe só, fique comigo, passe o dia comigo, venha à escola comigo, ao parque comigo, assista à televisão comigo, leia quadrinhos comigo, almoce comigo. (...) Nasci fora do meu país, no inverno, num dia 
N. 25 - 2013.1 - VAGNER LEITE RANGEL, FLAVIA MAIA BOMFIM, MARILENE S. COSTA, IZA QUELHAS

frio e cinzento. Duas horas de contração sem poder parir, porque eu não tinha virado e a anestesista não estava lá. Penou, a minha mãe, para me ter. E, quando eu vim ao mundo, ela nem pôde me segurar nos braços, tinhamlhe dado anestesia geral. Pior: quando acordou, percebeu que lhe tinham feito um corte na vertical. Teria para sempre a cicatriz do meu nascimento, um traço reto e em relevo unindo o vão entre os seios ao púbis. (...) Quando você nasceu, não estava frio nem cinzento. Não penei para parir. Não tomei anestesia, nem tenho cicatriz, você nasceu de parto normal. Eu a peguei nos braços imediatamente. Você foi muito querida e desejada, a resposta de um exílio sem dor. (LEVY, 2009, p. 22-26). [Grifos nossos].

Nestes momentos, a autoficção beira a confissão: o discurso se descola do eixo autobiográfico e se aproxima do "confessionalismo" romântico que, segundo Silviano Santiago (2011), ele, o discurso confessional, é marcado pelos resquícios de culpabilidade cristã:

Já o discurso propriamente confessional está ausente de meus escritos. Nestes não está em jogo a expressão despudorada e profunda de sentimentos e emoções secretos, pessoais e íntimos, julgados como os únicos verdadeiros por tantos escritores de índole romântica ou neo-romântica (SANTIAGO, 2011, p. 16-7).

\section{Outras viagens metafóricas}

Além da viagem metafórica que constrói imaginariamente intenso diálogo com a voz materna, há também outras viagens que não são necessariamente literais, como a paralisia, a viagem ao passado (a história do avô, a ditadura, a doença e o assassinato do parceiro após o período violento do relacionamento) que, por outro lado, também fazem parte do processo de escrita da personagem-narradora, bem como parte do insumo ficcional que possibilita a criação literária (SANTIAGO, 2011, p. 15-23):

Conto (crio) essa história dos meus antepassados, essa história das imigrações e suas perdas, essa história da chave de casa, da esperança de retornar ao lugar de onde eles saíram, mas nós duas (só nós duas) sabemos ser outro o motivo da minha paralisia. Conto (crio) essa história para dar algum sentido à imobilidade, para dar uma resposta ao mundo e, de alguma forma, a mim mesma, mas nós duas (só nós duas) conhecemos a verdade. Eu não nasci assim. Não nasci numa cadeira de rodas, não nasci velha. Nenhum passado veio me assoprar os ombros [...] (LEVY, 2009, p. 62). 
Daí que o título As chaves de casa de A chave de casa é uma brincadeira séria a respeito da busca da personagem por identificação. Cada viagem, que é uma busca (seja literal ou não), representaria uma possibilidade de se encontrar, isto é, a chave para sua redenção sem Deus. Busca que a move de sua aparente e suposta paralisia em direção aos desafios da alteridade (seja nacional ou estrangeira) que pode restituir a sua identidade ou não, uma vez que a morte da mãe e o relacionamento intenso (ora consentido ora não) lhe tiram o prazer de viver - o que podemos entender, num sentido figurado, como o próprio estado de paralisia relatado pela personagem. Em outras palavras, o outro aparece, para a personagem central, como um certame de integração consigo mesma a fim de não perecer:

Eu fiquei assim. Fui perdendo a mobilidade depois que você se foi. Depois que conheci a morte e ela me encarou com seus olhos de pedra. Foi a morte (a sua) que me tirou, um a um, os movimentos do corpo. Que me deixou paralisada nessa cama fétida de onde hoje não consigo sair (LEVY, 2009, p. $62)$.

Eu fiquei assim. Fui perdendo a mobilidade depois que o conheci. Depois que o amei: depois que conheci a loucura através do amor, o nosso. Foi o amor (excedido) que me tirou, um a um, os movimentos do corpo. Que me deixou paralisada nessa cama fétida de onde hoje não consigo sair (LEVY, 2009, p. 133).

\section{As chaves de leitura de A chave de Casa}

Fraturada fisicamente e emocionalmente por causa das agressões físicas do amado, além do desamparo psicológico causado pela perda da mãe, a personagem, com as viagens/buscas, anseia e ambiciona preencher as lacunas existenciais da vida, a partir do enfrentamento de sua própria paralisia. "Estou num ponto em que preciso mudar a direção do barco, ou então serei capturada pelo olhar de Medusa e me tornarei pedra, lançada ao mar." (LEVY, 2009, p. 10). É a autoficção em confronto com a confissão:

Você não pode partir. (...) Poderia argumentar que ainda há muitas coisas que não fizemos juntas. Que quando estiver triste não terei colo quente para me receber. Que quando tiver medo não poderei me esconder atrás da sua saia. Que não terei a quem dizer te amo infinitas vezes sem medo algum, sem receio. Porque só o nosso amor não tem medo. Poderia argumentar que há coisas que nunca lhe disse, coisas que quero dizer. Que você também deve ter histórias para me contar. Que quero você ao meu lado para ouvir as aventuras que ainda viverei. Que quero você ao meu lado quando eu publicar o meu primeiro livro. Que quero você ao meu lado quando eu conhecer o 
N. 25 - 2013.1 - VAGNER LEITE RANGEL, FLAVIA MAIA BOMFIM, MARILENE S. COSTA, IZA QUELHAS

meu príncipe encantado e com ele decidir que o amor é eterno. Que quero você ao meu lado quando nascer o meu primeiro filho, e também o segundo e o terceiro (LEVY, 2009, p. 71).

[Você nunca pensa em coisas boas? Não tem sonhos?] Tenho, claro que tenho. Sonho que um dia um príncipe chegará montado num cavalo branco para me buscar. Não precisarei fazer esforço algum, ele saberá que sou a mulher por quem procura. Bastará nos olharmos para saber que fomos feitos um para o outro (LEVY, 2009, p. 108).

Primeiro no Brasil, reavaliando o seu passado - o que caracteriza uma literatura autoficional, mas com tons confessionais por buscar a aceitação da mãe (SANTIAGO, 2011); depois no exterior, investindo em experiências que possam ajudá-la a recuperar seu passado (e quem sabe superar seus traumas), a personagem pode, então, preencher sua existência desapegada do mundo. Vide o almoço com a família turca, exemplificando o princípio de identificação cultural que, neste caso, não se dá através do idioma, mas sim da alimentação a tradição se concretiza pelo viés da refeição:

Apesar desse incidente inicial, aos poucos fui percebendo afinidades entre nós. Quando disse que em casa fazíamos aquela mesma comida, o Raphael avô se soltou um pouco, sorriu pela primeira vez, feito pensasse que o passado não está só na língua (LEVY, 2009, p. 160).

Além do relacionamento com o português, que exemplifica a possibilidade da nãoparalisia afetiva, o que caracterizaria o anseio de sair daquele estado de paralisia psicoemocional. Por outro lado, as personagens, a protagonista e o próprio português, parecem ter ciência da impossibilidade daquele caso amoroso:

Não sei quantas taças de vinho havíamos bebidos. Estávamos sem roupa havia muitas horas: nuinhos, como ele gosta de dizer. Esparramados no chão na cama no sofá. Falando de coisas sem importância, coisas muito importantes. Tocando o corpo um do outro suavemente, sem pressa. Sabíamos, os dois, da eternidade das horas que passavam. Perguntei-lhe: então, vem você morar no Rio ou venho eu para Lisboa? E rimos, os dois, rimos muito, gargalhamos. Também sabíamos da brevidade do tempo, o que nos permitia brincar como dois meninos, dois adolescentes que fazem planos mesmo quando têm certeza de que nunca se realizarão. (LEVY, 2009, p. 196).

\section{Os momentos: I've told every little star e Bang, Bang - My baby shot me down}


N. 25 - 2013.1 - VAGNER LEITE RANGEL, FLAVIA MAIA BOMFIM, MARILENE S. COSTA, IZA QUELHAS

Era sábado à noite, e a música estava no volume máximo. Eu dançava só de calcinha enquanto Linda Scott cantava I've told every little star. Uma cerveja na mão e várias latinhas vazias em cima da mesa. Dançar é como fazer sexo, eu disse antes de colocar a música. Você fingiu não me ouvir, não gostava de dançar.

Você não demorou para voltar, você não aguentava a sua solidão quando eu estava bem com a minha. Apareceu no corredor com o sorriso sarcástico de sempre, uma cerveja e um cigarro numas das mãos e um CD na outra. Desligou o som e disse: vou botar aquela música que você adora. Concordei, sorrindo, gostando da ideia, sem saber ainda que música seria. Você veio para perto de mim e [...] derramou um pouco de cerveja nos meus seios e me chupou o seio e perguntou: quer dizer que dançar é como fazer sexo? Eu ri, riso de bêbada, riso alegre, riso feliz. (...) Então pude ouvir a música, a nossa música. My baby shot me down. Você tinha um olhar que me aterrorizava. Bang Bang. Você mirou em mim e atirou, você nem precisava de arma, você atirava e atirava e atirava e tinha as mãos livres. Você me acertou e já não pude dançar, já não pude me mexer. Você se foi, me deixou novamente sozinha e eu nem soube por quê. Estirada no chão até o amanhecer, chorei a minha própria morte (LEVY, 2009, p. 183-4).

Num mesmo capítulo, há um diálogo com as músicas supracitadas. Enquanto na letra da música Bang, Bang - My baby shot me down a amada é ferida com armas, no romance a personagem é ferida através da privação de sua própria existência autônoma em relação ao seu duplo, o amor.

Nestes dois movimentos, que são análogos a Eros - pulsão de vida - e Tânatos pulsão de morte -, duas trilhas sonoras, marcam o desenrolar da trama: I've Told Every Little Star, de Linda Scott, e Bang Bang - my baby shot me down, de Nancy Sinatra. Entre as viagens e os movimentos da narrativa, as ações da personagem sugerem que as suas tentativas podem ser compreendidas como possíveis chaves de leitura e compreensão de sua vida ficcional, bem como da obra em questão. Da escrita autoficional a confessional, as músicas supracitadas marcam as fases da personagem na sua viagem de "regresso-sem-deus" ou metanarrativas à vida. I've Told Every Little Star simboliza a pulsão de vida:

[...] Naquele início, a paixão se manifestava como fome - de novidades, conversas, toques, sexo - eu queria engolir tudo que estivesse à minha frente, tudo o que viesse de você. E assim foi. Toquei a campainha. Suava. Minha camiseta molhada se colava ao busto, marcando levemente os seios. Quando você abriu a porta, eu não podia esconder o desejo de pular em cima de seu corpo, ali, no corredor de entrada da sua casa. Tenho certeza que você sentiu meu cheiro de sexo prestes. 


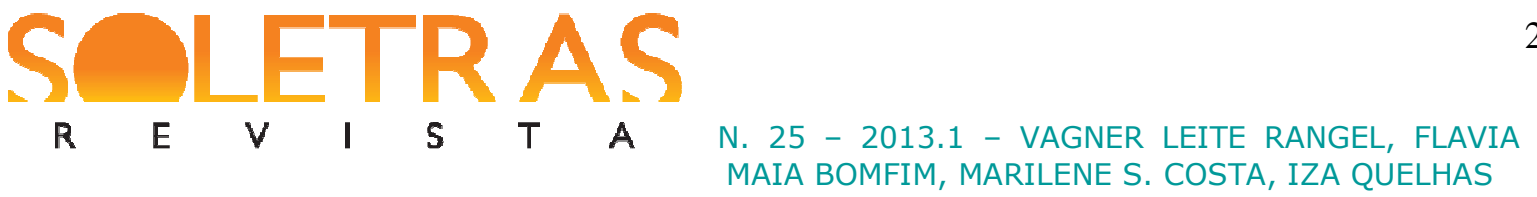

[...] Quanto mais seus dedos descobriam o caminho, mais vulnerável eu me sentia. Nesse momento sabia que não haveria mais volta, já estávamos amarrados. Sua língua estava em meus seios - um e outro -, contornando os mamilos, deixando-os quase tão encharcados quanto meu sexo, ainda à espera. [...] As pernas se abrindo ligeiramente, o convite já feito. E, como pude confirmar tantas outras vezes, poucas coisas me excitavam tanto quanto seus dedos afastando a parte de baixo da calcinha para um lado só, deixando meu sexo descoberto. Leve-me para a cama, eu disse. Você fingiu não ouvir. Com as duas mãos, levantou minha saía, arrancou minha calcinha e se abaixou aos poucos. Continuei de pé, enquanto você, ajoelhado, implorava não sei o que entre as minhas pernas, numa língua em que só vocês dois entendiam, o meu sexo e a sua boca (LEVY, 2009, p. 39-40).

Daí em diante, o casal vive uma unidade ímpar:

Morri de rir quando você disse que adorava mulher menstruada. Como assim adora? De que exatamente você gosta? Do cheiro? Da cor? Do gosto, você respondeu. $\mathrm{Ri}$, ensaiei uma cada de nojo: não, não pode ser. Sim, você me assegurou, pode, sim. Aguardei uns segundos, o tempo de saborear a resposta. Então vai (LEVY, 2009, p. 46).

No início eram assim: passávamos dias seguidos sem ver a luz do dia, trancados no quarto como se tivéssemos passado a vida esperando esse momento. Esquecíamos tudo o que havia do lado de fora e passávamos os dias e as noites na cama. (LEVY, 2009, p. 51).

Enquanto Bang Bang - my baby shot me down, simboliza os primeiros sinais de uma violência sexual não consentida até o ponto máximo da pulsão de morte. "Eu estava saindo do banheiro quando você me forçou a voltar. De frente para o espelho, eu admirava o reflexo do seu rosto enquanto você afastava as minhas pernas" (LEVY, 2009, p. 86).

O prazer de antes parece estar numa espécie de voyeurism, uma vez que o prazer do ato sexual descrito parece estar mais no olhar e menos no ato em si, ainda mais se comparado com as descrições anteriores:

Não sei se houve um momento específico em que as brigas começaram. Talvez elas tenham sido sempre inerentes a nós dois. Da mesma maneira que não conseguíamos viver sem o corpo um do outro, tampouco conseguíamos viver sem brigar. Às vezes nos machucávamos. Quase sempre terminávamos. Quase sempre você terminava, porque eu não saberia o que fazer com o meu corpo sem o seu. [...] Então, cada vez que percebia que eu estava apegada demais, você dizia: assim não dá, assim não quero, não sei o que fazer com tanta cobrança, precisamos de um tempo, precisamos viver cada um a sua vida. Eu me desesperava, eu berrava: a minha vida é a sua, a minha vida é a nossa. E durante horas continuávamos o que para um 
espectador seria apenas uma encenação, mas para mim é a própria experiência da morte (LEVY, 2009, p. 91).

Apesar de amá-lo, "Você me fazia gozar como homem algum. Você me fazia acreditar que era isso o amor. Eu acreditava que o amava. Acreditava que você me amava." (LEVY, 2009, p. 163). A personagem central adiante assume que "Entre nós não havia amor. Havia medo" (LEVY, 2009, p. 176).

\subsection{Autoficção como viagem metafórica autoavaliativa}

Sendo fruto de um trabalho intelectual, por parte do crítico, e literário, por parte do sujeito leitor, a autoficção é um encontro entre as forças criativas da imaginação leitora e da razão crítica, o que a torna essencialmente híbrida. Portanto, os discursos confessionais e autobiográficos são categorias distintas. Para fins didáticos, podemos dizer que o primeiro é de fora para dentro: desabafa e aguarda uma avaliação externa - o mundo exterior o pressiona, enquanto o segundo é de dentro para fora: se autoavalia e, assim, faz um balanço interno da vida - este lança sobre o mundo exterior o seu olhar interno. (SANTIAGO, 2011).

Ainda em "Meditação sobre o ofício de criar" (2011), Silviano Santiago discorre sobre a criação literária que tem como ponto de partida a autobiografia. Mas, para o crítico e autor de ficção, a distinção deve ser feita e respeitada, uma vez que o discurso autoficção não é o mesmo que o confessional. Diz ele:

[...] a expressão meramente confessional. Os dados autobiográficos servem de alicerce na hora de idealizar e compor meus escritos e, eventualmente, podem servir ao leitor para explicá-los. Traduz o contato reflexivo da subjetividade criadora com os fatos da realidade que me condicionam e os da existência que me conformam. Do ponto de vista da forma e do conteúdo, o discurso autobiográfico per se - na sua pureza - é tão proteiforme quanto camaleão e tão escorregadio quanto mercúrio, embora carregue um tremendo legado na literatura brasileira e na ocidental (SANTIAGO, 2011, p. 16).

Partindo da definição de Santiago (2011), podemos afirmar que o romance de Tatiana Salem Levy (2009) baseia-se no discurso autobiográfico, por trazer dados referentes à própria vida da autora como insumo ficcional, o que, por sua vez, possibilita a emergência da criação literária. Exemplificando, os dados da personagem e da autora são os mesmos: data e local de nascimento, Brasil, histórico familiar e morte da mãe por câncer. Por outro lado, não deixa de 
N. 25 - 2013.1 - VAGNER LEITE RANGEL, FLAVIA MAIA BOMFIM, MARILENE S. COSTA, IZA QUELHAS

ter acentos confessionais, uma vez que o diálogo com a "forjada" voz materna é parte integrante da trama:

[...] Tudo não passava de uma grande encenação: éramos judeus um dia por ano. Festejávamos o ano-novo, mas para nós o ano só começava no dia primeiro de janeiro. $\mathrm{O}$ ano nunca começou em setembro ou outubro. Então, por que a celebração? Por que esse teatro para nós mesmos? [Não entendo por que dizer que não havia verdade. Deus não estava na mesa, concordo, foi a nossa escolha. Não era a religião o que nos importava, mas a tradição. [...] $\mathrm{O}$ importante era manter a simbologia. Eu queria transmitir um pouquinho do que aprendi para os que vieram depois.] Eu sei. Entendo seu gesto, entendo sua intenção. Romper definitivamente com o passado é mais difícil do imaginamos, gera culpa, uma culpa que pode se tornar mortal [...]: temos medo de esquecer o passado e ser responsáveis por isso. [O passado não é para ser esquecido.] Se não esquecemos o passado não vivemos o presente. [...] [Não, minha filha, o que você suporta em seu dorso frágil são os silêncios do passado. Você carrega o que nunca foi falado, o que nunca foi ouvido. O silencio é perigoso, eu a alertei] (LEVY, 2009, p. 130-1).

\section{O outro como desafio pessoal a fim de preencher a lacuna existencial}

A chave de casa traz o outro - a alteridade - como um desafio pessoal, marcando a forte presença do discurso autoficcional no romance, além do intenso investimento num diálogo confessional com a voz materna, marcando o "confessionalismo" romântico.

Esta seção do trabalho dará mais atenção à alteridade que se concretiza através do relacionamento amoroso e violento da personagem central com o seu parceiro sexual, que representaria uma busca por integração afetiva - mais uma chave a fim de abrir a porta de sua própria redenção -, que é frustrada pela não correspondência do outro, configurando uma espécie de amor platônico contemporâneo.

Segundo o E-dicionário de termos literários, de Carlos Ceia (2013),

O conceito mais comum relativamente ao duplo é que este é algo que, tendo sido originário a partir de um indivíduo, adquire qualidade de projecção e posteriormente se vem a consubstanciar numa entidade autónoma que sobrevive ao sujeito no qual fundamentou a sua génese, partilhando com ele uma certa identificação. Nesta perspectiva, o DUPLO é uma entidade que duplica o "eu", destacando-se dele e autonomizando-se a partir desse desdobramento. Gera-se a partir do "eu" para de imediato, dele se individualizar e adquirir existência própria (CEIA, 2010). 
No romance, isso se realiza por meio da busca da personagem por completude através do sentimento que sente em relação ao parceiro. $\mathrm{O}$ amor quase à primeira vista parte dela para com ele. Daí ganha existência nele, no amado, que, então, torna-se autônomo em relação à ela. Ainda segundo o dicionário de Carlos Ceia (2010), "sua coexistência como o 'eu' de que é originário, contudo, nem sempre é pacífica." No ritmo da música Bang Bang - my baby shot me down, temos um exemplo da coexistência violenta entre o duplo:

Quando você aproximou docemente os lábios dos meus ouvidos, sabia que me faria um pedido, por isso me afastei, estava cansada dos seus pedidos. Você disfarçou, fingiu que não tinha percebido meu gesto e tentou se aproximar novamente. Eu disse não, não quero, estou casada dos seus pedidos. Você me apertou os pulsos, segurando-os com uma única mão. Assustada, gritei: solte-me! Você não me soltou. Com a ponta fina de um lápis que encontrou largado ao seu lado me rasgou a pele do braço. Um filete de sangue escorreu, manchando o sofá onde eu estava sentada. Berrei feito louca. Que você era um psicopata, doente mental, que batia em mulher, que eu ia à delegacia, que o odiava, tinha nojo, azia. Que você era um crápula, um animal, não era gente. Quando você me soltou, empurrei seu corpo com tanta força que encontrei e, com o indicador quase a esfregar seu rosto, disse sem pestanejar: da próxima vez arranco seus olhos. Os dois (LEVY, 2009, p. 119).

Apesar disso, o duplo apresenta outro aspecto: “(...) segundo o julgamento do "eu", características positivas, sendo resultante de um processo de identificação entre o "eu" e o seu DUPLO” (CEIA, 2010). Ela, então, passa a acreditar que aquilo que vive no relacionamento violento é de fato o amor:

Não sei se nos encontramos alguma vez, se houve algum momento em que pudemos dizer que o amor entre nós existia como certeza e felicidade, ou se apenas perambulamos um pela vida do outro como os personagens embaraçados de um certo cineasta chinês que mostra o amor como impossibilidade. Toda vez que vejo seus filmes, penso em nós, no nosso amor impossível, no nosso amor irrealizado apesar dos anos juntos, e me pergunto se haveria alguma chance de ter sido de outra maneira, ou se a força do nosso amor não estava justamente na sua impossibilidade (LEVY, 2009, p. 192).

Uma possível prova disso é que com o português ela se pergunta se aquilo é amor:

Então nos beijamos: um beijo terno, doce. E depois tivemos de ir embora, de mãos dadas, eu e ele, sabendo que na éramos eternos, que não éramos príncipe e princesa, mas que nossos lábios se entendiam, que as nossas bocas 
finas levemente coladas um à outra eram feito amor de príncipe e princesa. Era, talvez, o amor (LEVY, 2009, p. 192). [Grifos nossos].

Por outro lado, "o DUPLO apresenta, de acordo com o julgamento do 'eu', características negativas, resultantes de um processo de oposição entre o 'eu' e o seu DUPLO, pela constatação de uma não correspondência de traços ou características afins": embora o amor dela ganhe existência e, depois, autonomia nele, o amante, este não responde à altura e o sentimento torna-se uma espécie de amor platônico contemporâneo, isto é, friends with benefits but no strings attached, que é uma das reações da personagem que já citamos anteriormente: "Então, cada vez que percebia que eu estava apegada demais, você dizia: assim não dá, assim não quero, não sei o que fazer com tanta cobrança, precisamos de um tempo, precisamos viver cada um a sua vida" (LEVY, 2009, p. 91). Daí que, no romance, existe uma perfeita simbiose até o momento I've told every little star. No entanto, o momento Bang Bang - My baby shot me down é marcado pela predominância de atos de violência, seja o ato sexual não consentido ou agressão física:

Quando você aproximou docemente os lábios dos meus ouvidos, tive medo, muito medo. Tire a roupa. Tire a roupa toda e me espere na cama, você ordenou. Acuada, obedeci. Nesse dia você me possuiu de maneira que eu nem sabia existir. Nesse dia descobri que não era amor o que sentíamos (LEVY, 2009, p. 129).

Se a princípio temos a consubstanciação do amor - o personagem se une a personagem durante o momento: I've told every little star -, por outro lado, ele, o parceiro, adquire autonomia em relação à personagem central, ao passo que, paradoxalmente, mantém uma certa identificação e independência com a personagem, uma vez que o jogo dele se estabelece com ela. Na afirmação do duplo, o "eu" parece constatar uma correspondência de traços ou características afins: encaixe perfeito dos corpos; sexo sempre úmido e pronto; ambos os corpos se realizam sexualmente e idealmente. Na negação do duplo, o medo, a insegurança e a violência alimentam o sentimento de desamparo e frustração em relação ao outro.

Neste intercâmbio, podemos ler esta relação, por parte da personagem feminina, como um investimento numa procura por, se é possível dizer assim, "desfragmentar" a sua fragmentada condição identitária.

\section{Conclusão}


Por fim, a relação de amor e de dor dos personagens pode ser compreendida a partir da noção de simbiose, que é um termo da biologia, para simbolizar a relação de comensalismo: a relação na qual duas espécies de animais se encontram associadas com benefício para uma delas, mas sem prejuízo para a outra; e parasitismo, quando a interação entre duas espécies, na qual uma delas, o parasita, se beneficia da outra, o hospedeiro, causando-lhe danos de maior ou menor importância, mas raramente a morte. O primeiro momento da simbiose é positivo, bem ao tom da canção I've told every little star. Já o segundo, é negativo, não devendo nada ao tom de Bang bang - my baby shot me down.

Percebemos, ao longo da narrativa, o comensalismo, que representa o momento em que tanto o "eu" quanto o "duplo", além de viverem juntos, se beneficiam deste intercâmbio, e parasitismo, que representa o desequilíbrio entre o "eu" e o "duplo". No primeiro movimento, há uma tendência a uma espécie de androginia: o tão sonhado desejo de ser uma só carne se realiza, enquanto na segunda, há uma espécie de "desandroginia": os corpos se repelem. Mas, diferentemente do mito do andrógino, cuja separação leva a uma eterna e incansável busca do mesmo (da parte perdida na separação), o "eu” já não mais buscará a parte da qual se separou, mas escreverá outra narrativa (história de amor) ao acreditar que pode não ter encontrado o amor, que amar pode ser outra coisa, representado pelo encontro da narradora-personagem com o português, em Lisboa:

Perguntei-lhe pelo cavalo branco, ele disse não ter nenhum. E a roupa de príncipe? Também não tenho. E o nome de príncipe? Também não. Tem um buquê de flores então? Tampouco o tenho. Mas isso é fácil de resolver, espera um bocadinho. Quando voltou, trazia escondido atrás do corpo um buquê de flores do campo, de cores variadas, de cheiro bom. (...) as nossas bocas finas levemente coladas uma à outra eram feito amor de príncipe e princesa. Eram, talvez, o amor (LEVY, 2009, p. 193).

Não há mais "cavalo branco", "príncipe" nem sequer "buquê de flores" - talvez nunca tenha tido. Daí que a fala da personagem "Eram, talvez, o amor" (LEVY, 2009, p. 193) pode ser compreendida como uma mudança de postura diante das narrativas de completude: diminui-se o investimento na realização de tais sonhos, talvez porque, após experiências traumáticas que não podem ser esquecidas nem ignoradas, a impossibilidade de se ter certezas absolutas sobre a realidade parece ser a única certeza que lhe resta. 


\title{
Referências bibliográficas:
}

BARTHES, Roland. Mitologias. Rio de Janeiro: Difel, 2010.

BRANDÃO, Junito de Souza. Mitologia grega: v. III. Petrópolis, RJ: Vozes, 2004.

BRUNEL, Pierre. Dicionário de mitos literários. Rio de Janeiro: José Olympio, 1998.

CEIA, Carlos. E-dicionário de termos literários. Disponível em: http://www.edtl.com.pt/index.php?option=com_mtree\&task=viewlink\&link_id=778\&Itemid= 2. Acesso em 10 de Janeiro de 2013.

LEVY, Tatiana Salem. A chave de casa. Rio de Janeiro / São Paulo: Record. 2007.

MAINGUENEAU, Dominique. O discurso literário. São Paulo: Contexto, 2009.

SANTIAGO, Silviano. Meditação sobre o ofício de criar. Revista Gragoatá, n. 1, Niterói, RJ, Universidade Federal Fluminense, 1996, pp.

\section{The keys of the house in As chaves de casa, by Tatiana Salem Levy}

\begin{abstract}
This text is an effort to think about the literary production in the contemporary society under the label of autobiographical novels, confessional and autofiction, which are different categories that are weaved altogether in the literary work which goes back on its past to reassess the world and / or integrate the self into some sort of "redemption-withoutgod". Because the contemporary self, marked by fragmentation of infrastructure and superstructure that (used to) support the Modern Age, comes out in the so called post modernity society. Paradoxically, the myths, in the original sense of the word, are still present in the modern imagination no matter how the modern age has tried to put it out. Therefore, this work focus on A chave de casa, by Tatiana Salem Levy (2009), published by Record, and also on a literary and critical text by Silviano Santiago (2011), Meditação sobre o ato de criar.
\end{abstract}

Keywords: Contemporary literature. Autobiographical discourse. Confessional discourse. Autofiction. Identity.

Artigo recebido em: 17 de maio de 2013.

Artigo aprovado em: 25 de junho de 2013. 